\title{
Chiến lược kiến trúc đối với biến đổi khí hậu tại nhà ở nông thôn Vĩnh Long
}

\author{
Nguyễn Tiến Đạt ${ }^{1}$ \\ ${ }^{1}$ Khoa Kiến trúc, Trường ĐHXD Miền Tây

TỪ KHOÁ TÓM TẮT

Kiến trúc bền vững

Nhà ở nông thôn

Biến đổi khí hậu

\section{KEYWORDS}

Sustainable architecture

Rural housing

Climate change
Tại Đồng bằng sông Cửu Long (ĐBSCL), tỉnh Vĩnh Long hiện đang phải gánh chịu nhiều hậu quả về môi trường do ảnh hưởng của biến đổi khí hậu như nước biển dâng, xâm nhập mặn, sạt lở đất, mưa lũ thất thường và mưa dông. Bên cạnh đó, cùng với hiện tượng đô thị hóa các vùng nông thôn và sự thiếu định hướng trong giải pháp quy hoạch và kiến trúc đã dẫn đến loại hình nhà ở nông thôn (NONT) tại Vĩnh Long đang mất dần các đặc trưng mang tính bản địa và chưa thực sự phù hợp với những điều kiện địa phương. Kết quả khảo sát cho thấy, có 5 loại hình kiến trúc NONT điển hình tại tỉnh Vĩnh Long. Trong số năm loại hình nhà ở Vĩnh Long, biệt thự là loại hình duy nhất không bị ảnh hưởng bởi biến đổi khí hậu. Nhà ở theo tầng là loại hình không bị ảnh hưởng đáng kể bởi biến đổi khí hậu. Tuy nhiên, những ngôi nhà đường phố đang phải đối phó với những tác động của xói mòn sông và triều cường. Đặc biệt, nhà ở thuần nông và đơn sơ bị ảnh hưởng nặng nề bởi sạt lở đất, triều cường, xâm nhập mặn và lốc xoáy. Trên cơ sở mối quan hệ với các đặc điểm kiến trúc bản địa, điều kiện kinh tế, xã hội và môi trường của tỉnh Vĩnh Long, các giải pháp kiến trúc liên quan đến biến đổi khí hậu đã được đề xuất nhằm nâng cao chất lượng cuộc sống, giảm thiểu tác động xấu về môi trường và để đáp ứng nhu cầu phát triển bền vững trong tương lai.

\begin{abstract}
In the Mekong River Delta, Vinh Long province is currently suffering from envi-ronmental consequences due to the effects of climate change such as sea level rise, saline intrusion, landslides, erratic floods, and thunderstorms. Besides, along with the phenomenon of urbanization in rural areas and the lack of orientation in planning and architecture solutions, it has led to the rural housing in Vinh Long which is losing its indigenous characteristics and is not really suitable for local conditions. The survey result show that, there are five typical rural housing types in Vinh Long province. Among the five types of Vinh Long ru-ral housing, villas are the only ones not being affected by climate change. Tradi-tional housing is a type not significantly affected by climate change. Street hous-es, however, are dealing with the effects of river erosion and high tides. In partic-ular, pure-agricultural and simple housing are heavily affected by landslides, tidal surges, saline intrusion, and tornadoes. Based on the relationship with the charac-teristics of indigenous architecture, economic, social and environmental condi-tions of Vinh Long province, architectural solutions with regards to climate change have been proposed to improve the quality of life, to minimize the nega-tive impacts on the environment and to meet the needs of future sustainable development.
\end{abstract}

\section{1. Đặt vấn đề}

Ngày nay, biến đổi khí hậu đã dần trở thành một vấn đề toàn cầu lớn nhất hiện nay, đặt ra những mối đe dọa nghiêm trọng về môi trường và kinh tế xã hội trên hành tinh này. Sự thay đổi bất thường trong mô hình khí hậu đã gây ra ảnh hưởng tiêu cực đến các hệ thống tự nhiên và con người bao gồm tần suất ngày càng tăng của các sự kiện thời tiết khắc nghiệt, mực nước biển dâng và mất đa dạng sinh học (IPCC, 2018). Việt Nam không phải là một ngoại lệ khi được coi là một trong 5 quốc gia chịu ảnh hưởng nặng nề nhất của biến đổi khí hậu do có bờ biển dài, vùng đồng bằng trũng và đông dân cư. Đặc biệt, là một trong những vùng hạ lưu sông Cửu Long, tỉnh Vĩnh Long chịu nhiều hậu quả tiêu cực của biến đổi khí hậu như lũ lụt, hạn hán, sụt lún, xói mòn và nước biển dâng. Do đó, những vấn đề như vậy đã gây áp lực đáng kể lên công nghệ kỹ thuật của cơ sở hạ tầng đô thị, an sinh xã hội và sức khỏe con người. Hơn nữa, theo Báo cáo đánh giá lần thứ năm của IPCC (Ủy ban liên chính phủ về biến đổi khí hậu) về sự nóng lên toàn cầu trong những thập kỷ tới, biến đổi khí hậu đang trầm trọng hơn nhanh hơn so với các kịch bản dự đoán [4]. Chính vì vậy, phát triển bền vững nổi lên như một yếu tố quan trọng trong định hướng phát triển đô thị nhằm giảm thiểu tác hại đến môi trường và nâng cao chất lượng cuộc sống ở khu vực nông thôn.

Kết quả của sự tăng trưởng kinh tế, đô thị hóa và công nghiệp hóa; ngành xây dựng chắc chắn là một ngành đóng góp chính vào biến 
đổi khí hậu toàn cầu do phát thải khí nhà kính, tiêu thụ nhiều năng lượng và tài nguyên thiên nhiên. Trong bối cảnh hiện nay, khuyến khích toàn cầu ứng phó với những mối đe dọa của biến đổi khí hậu là việc làm quan trọng, các giải pháp nên được đề xuất trong ngành kiến trúc và xây dựng là rất cần thiết, đặc biệt là ở các vùng nông thôn dễ bị tổn thương bởi thiên tai với khả năng thích ứng thấp. Do đó, bài báo này nhằm đánh giá hiện trạng kiến trúc nhà ở nông thôn của tỉnh Vĩnh Long, nhằm đưa ra các chiến lược giải pháp kiến trúc bền vững đáp ứng nhu cầu phát triển trong tương lai, phù hợp với đặc điểm kinh tế, văn hóa, xã hội và khí hậu của vùng [2].

\section{2. Đánh giá kiến trúc nhà ở nông thôn}

Kết quả khảo sát tại tỉnh Vĩnh Long cho thấy hiện trạng NONT phân bố thưa thớt và có sự phát triển không đồng đều giữa các vùng. Nhiều khu vực làng xóm không bố trí thành cụm tập trung mà phân tán, kéo dài trên các kênh rạch. Những ngôi nhà ở truyền thống đã bị phá hủy nhiều, thay vào đó là các kiểu nhà hiện đại theo nhiều phong cách khác nhau. Nhà ở bán kiên cố chiếm tỷ lệ lớn (85,32 \%), còn lại là nhà kiên cố $(8,21$ \%), nhà thiếu kiên cố (4,66 \%) và nhà đơn sơ (1,81 \%) [2] (Bảng 1).
Bảng 1.

Hiện trạng về chất lượng nhà trên địa bàn Vĩnh Long tính đến $31 / 12 / 2019$ [2].

\begin{tabular}{|c|c|c|c|c|}
\hline \multicolumn{5}{|c|}{$\begin{array}{c}\text { Số hộ có nhà ở chia theo loại nhà ở } \\
\text { Đơn vị: căn nhà }\end{array}$} \\
\hline Tổng số & $\begin{array}{c}\text { Nhà kiên } \\
\text { cố }\end{array}$ & $\begin{array}{c}\text { Nhà bán kiên } \\
\text { cố }\end{array}$ & $\begin{array}{c}\text { Nhà thiếu } \\
\text { kiên cố }\end{array}$ & $\begin{array}{c}\text { Nhà đơn } \\
\text { sơ }\end{array}$ \\
\hline 299863 & 24610 & 255845 & 13972 & 5436 \\
$(100 \%)$ & $(8,21 \%)$ & $(85,32 \%)$ & $(4,66 \%)$ & $(1,81 \%)$ \\
\hline NONT & $\begin{array}{c}\text { Nhà ở biệt } \\
\text { thự vườn; } \\
\text { Nhà ở lô } \\
\text { phố }\end{array}$ & $\begin{array}{c}\text { Nhà ở truyền } \\
\text { thống; Nhà ờ } \\
\text { thuần nông }\end{array}$ & \multicolumn{3}{|c|}{ Nhà ở đơn sơ } \\
\hline
\end{tabular}

Các không gian chức năng trong căn nhà không còn được bố cục theo chiều ngang với ba gian hai chái giống nhà ở truyền thống mà thay vào đó là kiểu bố cục theo chiều sâu/dọc giống như nhà phố trong các đô thị. Phân loại theo chức năng sử dụng và điều kiện kinh tế hộ gia đình, tỉnh Vĩnh Long có 5 loại NONT gồm nhà ở biệt thự, nhà ở lô phố, nhà ở truyền thống, nhà ở thuần nông và nhà ở đơn sơ như thể hiện trong Bảng 1. Đặc điểm của từng loại NONT này được tổng hợp và phân tích trong những phần nội dung tiếp theo. Khi xem xét theo kiểu bố cục không gian tổng thể, mỗi loại nhà ở này lại có thể thành phân chia những loại riêng như thể hiện trong nội dung Bảng 2.

\section{Bảng 2.}

Phân loại NONT Vĩnh Long theo kiểu bố cục không gian tổng thể [1].

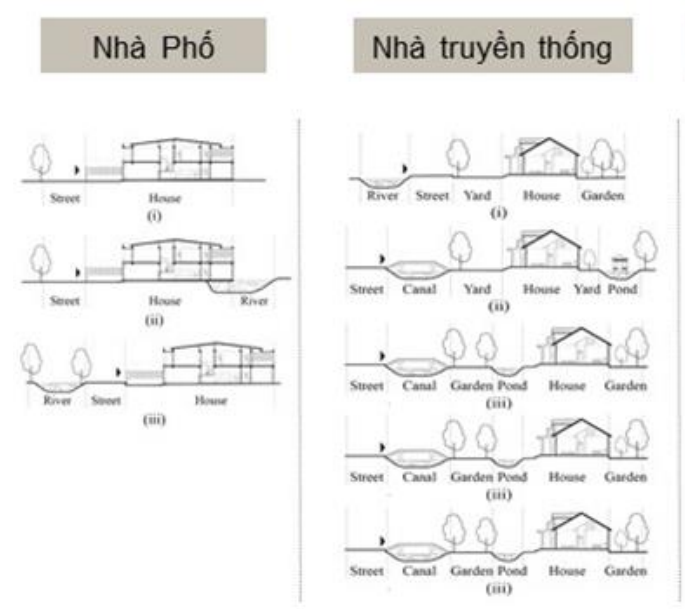

Nhà phố là loại hình nhà ở kết hợp chức năng ở và kinh doanh buôn bán. Do điều kiện phát triển kinh tế - xã hội và xu hướng đô thị hóa, đây là loại hình nhà ở tự phát, thường nằm ven đường hoặc ven sông nên chịu ảnh hưởng trực tiếp của biến đổi khí hậu (sạt lở, sông rạch, v.v). Tổ chức không gian có thể được chia thành ba bố cục khác nhau: (i) đường - nhà; (ii) đường - nhà - sông; (iii) sông - đường - nhà. Nhà cao 1-3 tầng, mái dốc hoặc mái bằng. Hướng của ngôi nhà chủ yếu đi theo trục giao thông chính. Nhà có kết cấu với hệ thống khung bê tông cốt thép kiên cố, chắc chắn bằng vật liệu mới. Do bố trí dọc theo chiều dài của ngôi nhà nên các không gian chức năng thiếu linh hoạt, không đảm bảo được sự thông thoáng tự nhiên. Không có không gian dành cho cây xanh do mật độ xây dựng dày.
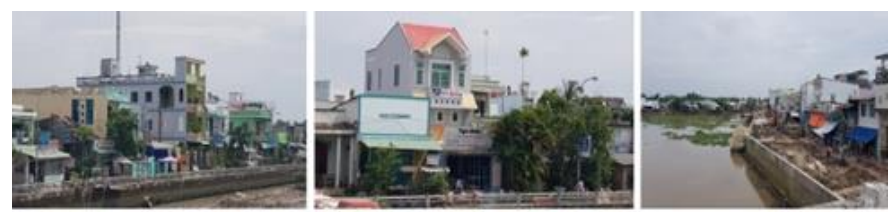

Hình 1. Hiện trạng nhà ở lô phố. 
Nhà truyền thống nằm rải rác quanh khu vực. Nó nằm dọc theo các tuyến đường giao thông hay kênh rạch và rất được quan tâm về hướng nhà. Trong khi đó, các làng nghề truyền thống phân bố tập trung dọc các tuyến sông, chủ yếu ở huyện Mang Thít. Mặt bằng ngôi nhà vẫn giữ cách bố trí 5 nhịp truyền thống, gồm phần chính và phần phụ. Tổ chức không gian có thể được chia thành ba bố cục khác nhau: (i) đường - sân - nhà - vườn - kênh - ruộng; (ii) sông - đường - vườn, sân - nhà ao - ruộng; (iii) đường - kênh - sân - nhà - ao, vườn - ruộng. Phần chính thường hướng ra hướng giao thông chính (đường hoặc kênh rạch), hướng về phía Nam, Tây Nam hoặc Đông Nam để tận dụng thông gió tự nhiên. Mái dốc 45o, thoát nước nhanh, chống dột với góc bức xạ mặt trời thấp. Cửa mái rộng và cao được tận dụng để cải thiện hệ thống thông gió và chiếu sáng. Xung quanh nhà được trồng cây xanh. Ngôi nhà kết cấu khung gỗ, không có móng sâu, cột được đặt trên đá hoặc xi măng, trong một số trường hợp, cột được chôn trực tiếp dưới đất. Ngoài ra, tại khu vực rạch Cai Thầy, huyện Mang Thít và huyện Long Hồ, nhà ở làng nghề truyền thống có thêm chức năng nung gạch men nên có thêm khu lò nung để sản xuất. Nhà chính có thể bố trí riêng biệt hoặc trong khu sản xuất. Vật liệu địa phương chủ yếu được sử dụng như gạch nung và đất sét. Có hai kiểu bố cục tổng thể: (i) đường - sân - nhà - sản xuất - kênh; và (ii) nhà - đường - sân - sản xuất - kênh. Không gian trong nhà không được thông gió vì tiếp giáp với khu sản xuất. Khí thải từ các lò gạch có ảnh hưởng trực tiếp đến môi trường xung quanh.

Nhà thuần nông dành cho các gia đình sinh sống bằng nghề sản xuất nông nghiệp. Chiếm số lượng nhà ở nông thôn lớn nhất ở Vĩnh Long, loại hình nhà ở này chủ yếu phân bố dọc theo sông, kênh hoặc các tuyến đường giao thông. Cũng giống như kiểu nhà truyền thống, mặt bằng ngôi nhà bao gồm các phần chính và phụ, kết hợp với phong cách kiến trúc hiện đại do tác động của quá trình đô thị hóa. Có bốn kiểu bố trí điển hình bao gồm: (i) đường - sân - nhà - vườn, chăn nuôi - kênh đào; (ii) đường - kênh - vườn - nhà - sân - kênh; (iii) kênh đường - sân - nhà - ao - vườn - ruộng; (iv) kênh - đường - sân - nhà - ao - vật nuôi. Nhà 1 tầng với mái dốc hoặc bằng phẳng được lợp bằng tôn hoặc ngói. Kết cấu khung gỗ, tường gạch không sơn nên khả năng cách nhiệt kém, thấm dột vào mùa mưa. Dễ bị ngập úng vào mùa mưa do nền đất khá thấp. Trong thời gian gần đây, do biến đổi khí hậu, xâm nhập mặn và triều cường đã ảnh hưởng trực tiếp đến nguồn nước tưới tiêu và sinh hoạt của người dân. Vì vậy, việc đưa ra các giải pháp giúp người dân cải thiện nguồn nước sinh hoạt và tích trữ trong tương lai là rất cần thiết.
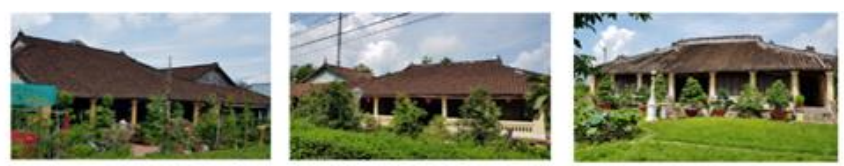

Hình 2. Hiện trạng nhà ở truyền thống.

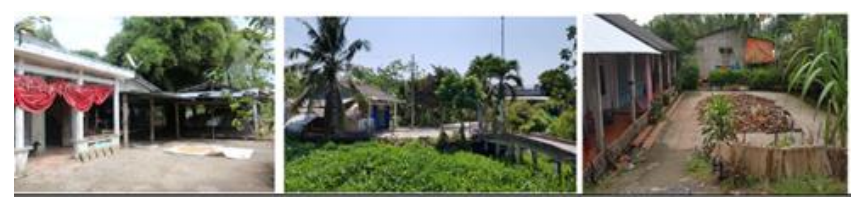

Hình 3. Hiện trạng nhà ở thuần nông.
Biệt thự vườn thường được xây dựng ở những khu đất rộng có thể đi lại bằng đường thủy hoặc đường bộ. Loại hình nhà ở này nằm rải rác từ trung tâm xã đến các khu vực ngoại thành dân cư thưa thớt. Mặt bằng ngôi nhà theo kiểu tập trung, có gian phụ bố trí xung quanh nhà chính. Chức năng chính của loại hình nhà ở này là một nơi ở. Mặt bằng ngôi nhà đa dạng với khoảng sân, vườn cảnh, vườn cây ăn trái và mặt nước. Có ba kiểu bố cục không gian: (i) sông - đường - sân - nhà vườn; (ii) đường - kênh - sân - nhà - sân - ao; (iii) đường - kênh - sân, vườn - ao - nhà - vườn. Các không gian sống đầy đủ tiện nghi có diện tích lớn hơn so với nhà ở thành thị. Ngôi nhà có từ 1 đến 3 tầng với phong cách kiến trúc hiện đại. Kết cấu khung bê tông cốt thép vững chắc và lớp vỏ công trình chắc chắn giúp công trình hoàn toàn chịu được ảnh hưởng lớn của thời tiết, lũ lụt, thủy triều và tác động của biến đổi khí hậu.

Nhà ở đơn sơ nằm trong khu dân cư lấn chiếm sông rạch hoặc nằm rải rác trên các cánh đồng ở vùng sâu, vùng xa. Mặt bằng nhà tương đối nhỏ hình vuông hoặc hình chữ nhật. Tổ chức không gian có thể được chia thành ba bố cục: (i) kênh - đường - ruộng - nhà - ruộng; (ii) đường - sân - nhà - vườn - kênh; (iii) đường - nhà - kênh. Không gian sinh hoạt chung khá hạn chế gồm phòng khách kết hợp thờ, phòng ngủ và bếp, không có gian phụ. Nhà cao 1 tầng với mái dốc và kiến trúc đơn giản. Kết cấu ngôi nhà khá tạm bợ với vách lá hoặc gỗ, lợp tôn tạm bợ và không có khả năng cách nhiệt. Điểm lại, nguồn nước tưới và sinh hoạt của người dân sống trong loại hình nhà ở này đã và đang bị ảnh hưởng trực tiếp bởi hiện tượng xâm nhập và triều cường do ảnh hưởng của biến đổi khí hậu.

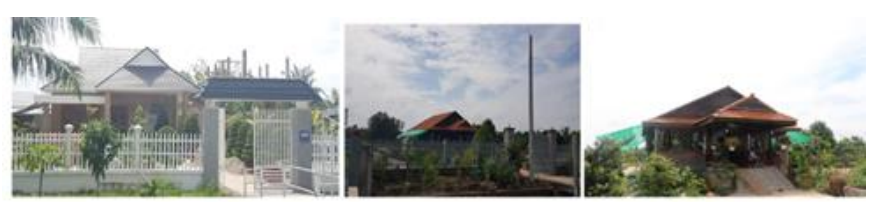

Hình 4. Hiện trạng nhà ở biệt thự vườn.

\section{Chiến lược giải pháp kiến trúc đối với biến đổi khí hậu}

Theo IPCC hoạt động của con người ước tính đóng góp làm tăng xấp xỉ $1,0^{\circ} \mathrm{C}$ vào sự nóng lên toàn cầu so với thời kì tiền công nghiệp, với ngưỡng trong khoảng 0,8 đến $1,2{ }^{\circ} \mathrm{C}$; Nóng lên toàn cầu có xu hướng tăng tới $1,5{ }^{\circ} \mathrm{C}$ vào giai đoạn 2030 - 2052 nếu nó tiếp tục giữ nguyên xu thế ở tỉ lệ hiện nay và các kịch bản ấm lên dường như tồi tệ hơn nhiều so với ước tính trước đây vào cuối năm này thế kỷ (Hình 5). IPCC cũng dự đoán rằng mực nước biển sẽ tăng trong khoảng từ 0,18 $\mathrm{m}$ đến $0,59 \mathrm{~m}$ vào cuối thế kỷ 21 . Bên cạnh đó, những diễn biến hạn hán kéo dài tại Vĩnh Long dẫn đến xâm nhập mặn đang dần trở nên rõ nét vào cuối năm 2019 cho đến nay [3], các kết quả mô phỏng xâm nhập mặn được phân tích gần như tương đồng so với dự báo. Vì vậy, việc đưa ra các giải pháp giảm thiểu và thích ứng với tác động của biến đổi khí hậu là vô cùng cấp thiết. Cần có các chiến lược giảm thiểu và thích ứng, cụ thể là trong môi trường xây dựng, để đối phó với vấn đề này. 
Các chiến lược giảm thiểu là các hành động liên quan đến việc giảm thiểu rủi ro lâu dài của sự thay đổi khí hậu đối với đời sống con người và nhằm giảm lượng khí thải $\mathrm{CO}_{2}$. Trong ngành xây dựng, chúng ta có thể đạt được mức giảm thiểu bằng nhiều giải pháp khác nhau bao gồm công nghệ tiên tiến; tài nguyên; phương pháp thiết kế và xây dựng. Cải tạo năng lượng là yếu tố đóng góp chính bằng cách tích hợp công nghệ hiệu quả mới trong sản xuất năng lượng xây dựng, giảm vận chuyển vật liệu xây dựng bằng cách sử dụng tài nguyên địa phương sẵn có, tận dụng năng lượng tái tạo. Ngoài ra, thiết kế kiến trúc NONT cần tích hợp với các kỹ thuật chủ động và thụ động có thể tối ưu hóa sự thoải mái trong cuộc sống của người sử dụng và giảm nhu cầu năng lượng cho việc làm mát, sưởi ấm và chiếu sáng. Điều này đòi hỏi phải xem xét các đặc điểm địa phương bao gồm điều kiện khí hậu.

Chiến lược thích ứng đề cập đến các hành động được thực hiện để giảm bớt thiệt hại có thể xảy ra, giải quyết hậu quả và khai thác bất kỳ lợi ích tiềm năng nào. Như đã trình bày trong phần trước; nhà mặt phố, nhà thuần nông, nhà đơn sơ được coi là một trong những loại hình nhà ở chịu ảnh hưởng nặng nề nhất của biến đổi khí hậu; sạt lở đất, triều cường, xâm nhập mặn và lũ lụt. Cần có những giải pháp phù hợp với văn hóa địa phương cũng như địa hình và khí hậu khu vực tạo cho khu vực nông thôn có khả năng chống chịu với các điều kiện thay đổi. Thứ nhất, để đảm bảo an toàn về nơi tránh trú khi có bão lớn, cần chuyển các khu dân cư tự phát, phân tán ven sông, biển vào nội địa, có cao độ nền. Các khu dân cư tập trung với hệ thống cơ sở hạ tầng đồng bộ và các công trình kiến trúc kiên cố làm nơi trú ẩn cho người dân sơ tán sẽ cải thiện điều kiện sinh hoạt, sản xuất cũng như cứu hộ. Thứ hai, các xã, thị trấn cần tăng cường trồng rừng phòng hộ, "phủ xanh" bãi sông bằng cách tạo dải cây xanh 7-10 m ven kênh, rạch để bảo vệ rãnh thoát nước, chống sạt lở. Các tuyến đường, ngõ xóm được thiết kế hệ thống cống rãnh hiệu quả đảm bảo thoát nước nhanh vào mùa mưa. Thứ ba, hệ thống thu gom và khai thác nước mưa cũng được đánh giá là giúp người dân chủ động nguồn nước khi xâm nhập mặn. Cuối cùng, kiến trúc nhà ở được coi là giải pháp có ảnh hưởng lớn nhất trong việc thích ứng với sự biến động của khí hậu. Lớp bao che được khuyến khích sử dụng vật liệu thân thiện với môi trường địa phương như gạch không nung, tôn chống nóng... có khả năng thông gió và chiếu sáng tự nhiên. Kết cấu nhà ở cần được thiết kế kiên cố hơn đối với nhà xây mới và hỗ trợ thêm hệ thống giằng để công trình có thể chống chịu được khi có bão, lũ. Hơn nữa, các tổ chức linh hoạt của các không gian chức năng được thông qua để điều chỉnh môi trường sống phù hợp khi thiên tai xảy ra; ví dụ, nhà có gác xép, nhà nổi. Cụ thể, Hình 7 dưới đây minh họa mô hình giải pháp cho nhà thuần nông, nhà đơn sơ và nhà mặt phố, những loại hình nhà ở bị ảnh hưởng nhiều nhất bởi biến đổi khí hậu.

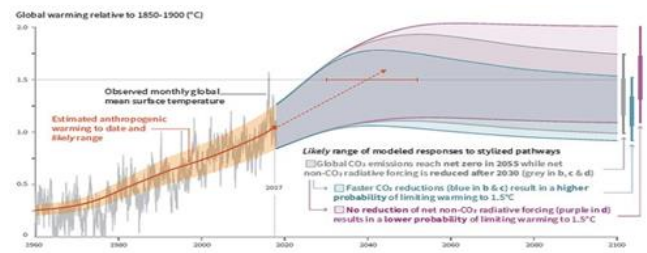

Hình 5. Quá trình nóng lên toàn cầu từ năm 1960-2020 và các dự báo đến năm 2100 [3].
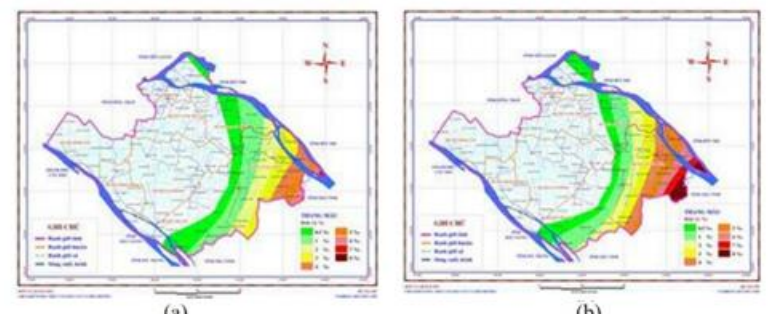

(b)

Hình 6. Quá trình xâm nhập mặn tại Vĩnh Long vào năm 2020 và dự báo năm 2030: (a) 2020; (b) 2030 [3].

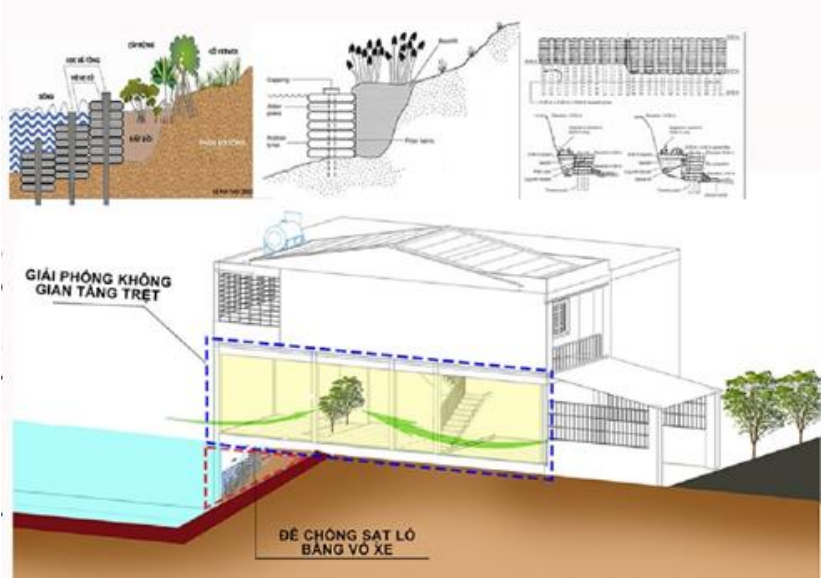

Hình 7. Mô hình nhà ở trệt bỏ trống và hệ thống đê được gia cố bằng lốp xe.

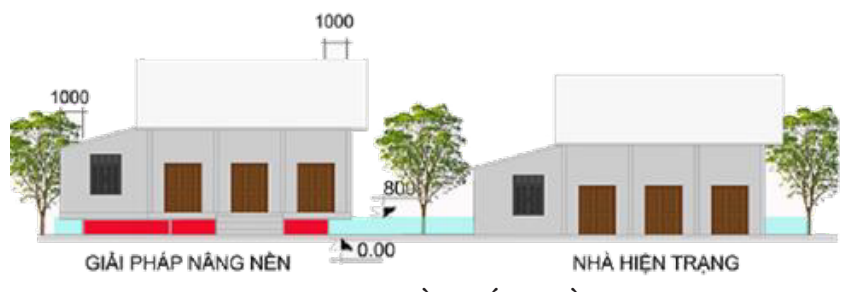

Hình 8. Giải pháp nâng nền chống triều cường dâng.
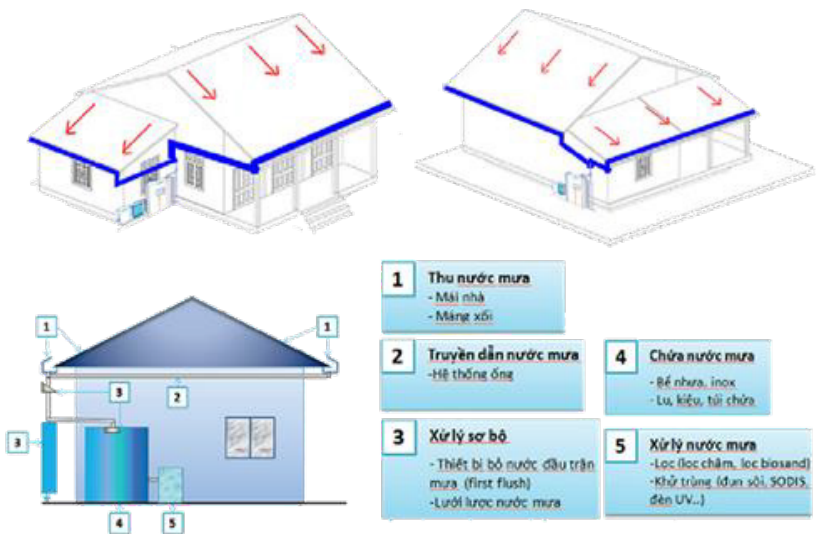

Hình 9. Hệ thống thu gom và xử lý nước mưa.

Các giải pháp đề xuất cho nhà mặt phố là cần thiết với sự thay đổi của thời tiết và giảm tác động tiêu cực từ triều cường dâng. Đối với nhà ở vùng trũng ở các huyện Long Hồ, Bình Tân, Tam Bình, và Mang Thit, không gian tầng trệt nên bỏ trống, dựa trên bài học của Le Corbusier 
(Hình 7). Có nhiều sự thuận lợi như (i) tầng trên sẽ là nơi trú ẩn trong trường hợp lũ lụt; (ii) thông gió tự nhiên được tận dụng vào ngôi nhà, giảm cản trở luồng không khí sang các ngôi nhà khác; (iii) tăng mật độ cây xanh cho khu vực, kết nối hệ thống sinh thái giữa môi trường bên trong và bên ngoài; (iv) thương mại hoặc sản xuất nhỏ được tận dụng ở tầng trệt. Đối với khu dân cư có mặt sau giáp sông bị sạt lở, cần gia cố hệ thống đê bao bằng phương pháp săm lốp. Mặc dù đê được gia cố bằng lốp xe có thể được coi là một giải pháp tạm thời, nhưng việc tận dụng các vật liệu tái chế và các vật liệu sẵn có của địa phương, giúp giảm chi phí so với việc xây dựng đê bê tông.

Do bị ảnh hưởng bởi lũ lụt và xâm nhập mặn, nhà thuần nông có thể áp dụng giải pháp nâng cao độ nhà kết hợp với hệ thống thu gom và xử lý nước mưa. Nền nhà được nâng lên $0,8 \mathrm{~m}$ và đẩy vào bên trong $1 \mathrm{~m}$ để chống ngập khi mưa bão. Nó giúp xua đuổi côn trùng, chuột, rắn ... mà còn tạo sự thông thoáng cho phần thấp của ngôi nhà cũng như tạo ranh giới mềm cho không gian bên trong và bên ngoài (Hình 8). Ngoài ra, khi áp dụng hệ thống thu gom và xử lý nước mưa, người dân sinh sống có thể tận dụng tối đa nguồn nước tự nhiên, góp phần cải thiện nguồn nước sinh hoạt, nguồn nước tưới tiêu và trong mùa khô hạn, xâm nhập mặn (Hình 9).

\section{Kết luận}

Bài báo này cho thấy, kiến trúc nhà ở nông thôn ở Vĩnh Long đang phải đối mặt với những vấn đề lớn về tiện nghi sinh hoạt và tổ chức không gian, đặc biệt là ảnh hưởng của biến đổi khí hậu. Nếu không có định hướng hoặc quản lý về điều kiện chất lượng sống, cư dân xung quanh khu vực đang phải chịu nhiều hiểm họa tự nhiên khác nhau như một chuỗi liên kết của biến đổi khí hậu. Vì lý do đó, các chiến lược giảm thiểu kiến trúc và thích ứng đã được đề xuất với nỗ lực giảm thiểu tác động tiêu cực của những thách thức đó; tuy nhiên, có những khó khăn và hạn chế cần nêu. Do đó, cần có các cuộc điều tra và thử nghiệm chi tiết hơn để áp dụng trong tương lai các phát hiện và giải pháp đề xuất được trình bày trong bài báo này. Nghiên cứu này sẽ là điểm khởi đầu trong nỗ lực cải thiện từng bước môi trường sống của con người và bảo vệ chính chúng ta cũng như thế hệ tiếp theo khỏi sự thay đổi của khí hậu.

\section{Tài liệu tham khảo}

[1]. Đặng Hải Đăng, Giải pháp kiến trúc cho nhà ở nông thôn tại Vĩnh Long, Trường Đại Học Kiến Trúc TP.HCM, Luận văn thạc sĩ, 2019.

[2]. Nguyễn Thanh Hải, Phạm Văn Cư , Thuyết minh tổng hợp Quy hoạch xây dựng vùng tỉnh Vĩnh Long đến năm 2030, tầm nhìn đến năm 2050, Bộ Xây dựng - Viện quy hoạch xây dựng Miền Nam., 2018.

[3]. Lê Thị Phụng, Nguyễn Kỳ Phùng, Bùi Chí Nam, Trần Xuân Hoàng, Lê Ngọc Tuấn, Ảnh hưởng của biến đổi khí hậu đến xâm nhập mặn ở tỉnh Vĩnh Long, Tạp chí Khí tượng thủy văn, trang 8-15, số 02/2020.

[4]. Ủy ban liên chính phủ về Biến đổi khí hậu (IPCC), Báo cáo đặc biệt về tình trạng ấm lên toàn cầu $1,5^{\circ} \mathrm{C}, 2020$. 